\title{
Comorbidities impact and de-prescribing in elderly with HCV-related liver disease: analysis of a prospective cohort
}

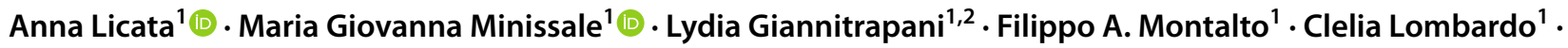 \\ Luigi Mirarchi $^{1}$ - Simona Amodeo ${ }^{1}$ - Maurizio Soresi ${ }^{1}$ - Giuseppe Montalto ${ }^{1}$
}

Received: 4 February 2021 / Accepted: 9 April 2021 / Published online: 28 April 2021

(c) The Author(s) 2021

\begin{abstract}
Management for HCV has undergone a notable change using direct-acting antiviral drugs (DAAs), which are safe and effective even in elderly. Here, we define impact of comorbidities, concomitant medication and drug-drug interactions in elder patients with HCV related disease before starting DAAs regimen. We analyzed data of 814 patients prospectively enrolled at our Unit within the web based model HCV Sicily Network. Out of 814, 590 were treated with DAAs and 414 of them were older than 65 years. We divided those 414 in two groups, one including 215 patients, aged between 65 and 74 years, and another with 199 patients, aged of 75 years and over. Charlson Comorbidity Index (CCI) was assessed for each patient; drug-drug interactions (DDI) and de-prescribing process were carried out appropriately. Within 414 patients included, percentage rates of women treated was higher than males, BMI was lower and cirrhosis was frequently reported in patients older than 75 years. Hypertension, diabetes mellitus, dyslipidemia $(p<0.0001)$, prostatic pathologies, kidney disease, gastrointestinal disease $(p<0.0001)$, osteoporosis $(p<0.01)$ and depression were most common co-morbidities. CCI showed lower scores in the first group as compared with the second one $(p<0.0001)$. Among drugs, statins were frequently suspended and anti-hypertensive often replaced. DAAs are useful and effective regardless of disease severity, comorbidities, medications and age. De-prescribing allows a stable reduction of number of medications taken with real improvement of quality of life.
\end{abstract}

Keywords $\mathrm{HCV} \cdot$ Elderly $\cdot$ Co-morbidities $\cdot$ Charlson Index $\cdot$ DDI interactions $\cdot$ De-prescribing

\section{Introduction}

Hepatitis $\mathrm{C}$ virus infection affects many individuals worldwide and its prevalence increases with aging [1-3] . Accordingly, most of the actually infected subjects are old, being born between 1945 and 1965 [4]. However, HCV morbidity and mortality rates could be underestimated because of concomitant disease. Clinical heterogeneity and genotypic mutation capacity are probably involved in the high rate of chronicity of the infection [5], and due to the high prevalence

Anna Licata

anna.licata@unipa.it

1 Internal Medicine and Hepatology, Department of Health Promotion Sciences, Maternal and Infant Care, Internal Medicine and Medical Specialties, PROMISE, University of Palermo Medical School, Piazza delle Cliniche 2, 90127 Palermo, Italy

2 Instiute for Biomedica Research and Innovation, National Research Council (CNR), 90146 Palermo, Italy of the disease in elderly, older patients constitute the main "reservoir" of the virus. Marcellin et al., investigating risk factors responsible of fibrosis progression in chronic hepatitis $\mathrm{C}$, showed that age, alcohol consumption and male sex were associated with a faster course of disease [6]. Thus, age in elderly represents an important factor predicting disease progression [2-8].

For many years, interferon (IFN) and ribavirin were the only antiviral therapies available for treatment of $\mathrm{HCV}$ infection. However, due to wide range of side effects, these drugs were often contraindicated, especially in elderly with comorbidities $[9,10]$. Direct acting antiviral agents (DAAs) have radically changed the clinical scenario of HCV management, even in the elder patients, regardless of stage of liver disease and IFN ineligibility [11, 12]. Safe treatment of patients aged of 65 years and over suggests that sustained viral response (SVR) rates are independent of age, and the contraindication eventually comes from drug interactions with medications taken for comorbidities [13, 14]. 
Aging, is usually accompanied by increasing presence of co-morbidities, such as hypertension, diabetes, cardiovascular and kidney diseases, which are causes of death [15]. Accordingly, the wide number of medications taken and, their interactions with DAAs, are crucial in the therapeutic choice of DAAs regimen. Load of comorbidities of elder HCV patients could be assessed by different scoring system, as Charlson Comorbidity Index (CCI) [16]. Searching DAAs-drug interactions could be achieved by Liverpool Interaction Checker at: www.hep-drugintera ctions.org [17]. However, eliminating or reducing certain medication, not only in the elderly patient, represents an optimal strategy to decrease inappropriate use of drugs. "De-prescribing" process is the most effective way to reduce the risk of adverse events from drug-drug interactions [18, 19].

Therefore, aiming to evaluate the impact of co-morbidities in patients of 65 years and over, affected by HCVrelated liver disease, we analyzed our prospective cohort including 590 patients who already achieved viral response and are still in follow-up. Furthermore, to eliminate potential drug interactions, we checked all medications taken and to maximize the efficacy of antiviral therapy, avoiding any treatment interruption or onset of adverse events, we properly start de-prescribing process.

\section{Methods}

\section{Study cohort}

In this prospective cohort study, we included patients treated for HCV-related liver disease from April 2015 to December 2019. Data were collected within the web-based model HCV Sicily Network [20]. For all, we collected clinical, laboratory and anthropometric parameters. Data regarding HCV genotype and viral load, HBV and HIV co-infections were assessed, as well.

Laboratory tests and visits were performed at the time of inclusion and every 4 weeks after starting antiviral therapy and finally 12 weeks after the end of the treatment, monitoring hemoglobin, platelets, ALT, albumin, serum glucose, serum creatinine, blood urea nitrogen and INR. Within 6 months preceding antiviral therapy prescription, patients enrolled were assessed by liver ultrasound. In those with cirrhosis, an endoscopy to search for esophageal varices was performed. Liver stiffness of all included patients was measured at inclusion; SVR (HCVRNA $<15 \mathrm{IU} / \mathrm{ml}$ ) was assessed at the end of therapy (8 vs. 12 weeks). All patients, after clinical assessment were candidates to antiviral regimen according to AIFA criteria for DAAs prescription (www.aifa.gov.it/web/guest/-/ registri-aifa). Treatment schedule, was chosen based on the viral HCV genotype, staging of liver disease and previous antiviral treatment [1].

\section{Assessment of comorbidity, drug-drug interaction and de-prescribing}

At inclusion and before DAA prescription, all patients were searched for the associated co-morbidities and medications taken. Comorbidity evaluation was performed through the Charlson Comorbidity Index (CCI), a score system useful for the clinical decision-making process, which allows to evaluate the total comorbidity load present in each patient. For each comorbidity present, a numeric score ranging from 1 to 6 was assigned according to their effect on mortality and the total score estimates survival at 10 years [16].

After recording the therapies taken for comorbidities, the presence of potential drug-drug interactions, which could interfere with antiviral regimen was assessed by Liverpool Interaction Checker at website: https://www. hep-druginteractions.org. Potential drug-drug interactions were collected and coded with different risk ranging from 0 (interaction has not been assessed), 1 (no clinically significant interaction expected), 2 (potential interaction that may require monitoring) up to 3 (co-administration is not recommended or contraindicated). Replacement, closely monitoring and "de-prescribing" of the drug, were evaluated in patients belonging to category 2 and 3 [21-23].

De-prescribing is a systematic identification process and "discontinuation" of drugs or drug regimens in circumstances in which obvious or potential negative effects exceed current and/or potential benefits, taking into account the goals of care, the life expectancy, values and preferences of the individual patient [23]. This process has been carried-out through the revision of all medications taken from the patients, assessment of risk/benefit of each drug and suspension/replacement of that medication which potentially could interact with antiviral therapy. Suspension and/or replacement of drugs have been closely carried out, through the use of diaries compiled by the patient (e.g., reporting blood pressure values every day if the suspended drug was an anti-hypertensive).

The study was conducted according to the Declaration of Helsinki. The ethics committee of the University Hospital AOUP Policlinico "P.Giaccone" approved the analysis of anonymous patient data; each included patient signed written informed consent. 


\section{Statistical analysis}

Data with normal distribution were expressed as mean and standard deviation (SD), otherwise as median and range and analyzed, respectively, with Student's $t$ or Mann Whitney $U$ Test. The difference between the frequencies was assessed with the Fisher exact test or with the chi square test. The results were considered significant if $p<0.05$.

\section{Results}

\section{Study population and baseline characteristics}

Given a total of 814 patients followed at our Internal Medicine and Hepatology Unit and included in the HCV Sicilian Network, those already treated with antiviral therapy were 590. Of these 414 (70\%), who were over 65 years of age, represented our study population. Patients included were divided in two groups: a group with age between 65 and 74 years and another with an age over than 75 $(\geq 75)$. Demographic, clinical and laboratory features are shown in Table 1. Percentage rate of woman treated was higher in both groups. BMI was significantly lower in older patients $(p<0.00001)$. Platelets count was lower in the group of older patients $(p<0.05)$ and accordingly cirrhosis, whereas chronic hepatitis was significantly more frequent in the first group (Table 1).

\section{Efficacy and safety profile of DAAs in elderly}

Based on the obtained results from clinical and laboratory tests, the choice of the most suitable DAAs treatment schedule was made for each patient. In both groups, the most prescribed regimen was the association of sofosbuvir/velpatasvir, followed by glecaprevir/pibrentasvir. Prescription of elbasvir/grazoprevir was more common in the group of patients over 75, as compared with those 65-74 $(p<0.004)$. At the end of therapy, HCV-RNA viral load was performed to verify SVR, which was $96.3 \%$ in the first group and $97.5 \%$ in the second.

Eight out of 215 (3.7\%) did not reach SVR: four patients did not finish treatment, two drop-out and two due to side adverse effects (SAEs). Regard patients with SAEs they were both women: one showed severe thrombocytopenia at 4 weeks from starting therapy with PLTs less than 3000/ $\mathrm{mmc}$ and the other showed edema and redness of the left upper arm after 7 weeks; one patient did not respond to therapy and three relapsed. Within the second group, 5 out of 199 (2.5\%) did not reach SVR: three did not finish therapy due to side effects (two patients for progression of renal damage with increase of serum creatinine, one due to increase of alanine-aminotrasferases more than 7 times ULN); one patient did not respond to therapy and another patient relapsed (Supplementary Table).

\section{Assessment of Charlson Comorbidities Index, comparison by age groups}

For all patients, comorbidities and concomitant medication were analyzed. Given the two groups, patients were divided according to the number of concomitant disease (Table 2).

Assessment of Charlson Comorbidity Index (CCI) in the study population showed lower scores in the first group of patients aged between 65 and 74, whereas higher scores prevail in the second. Sixty-one percent of the patients in the first group presented an index score less than 5 , whereas in the second group, more than $50 \%$ showed a score of $6-8$. A comparison between groups showed difference statistically significant between scores (3-5) $p>0.0001,6-8(p<0.005)$, $9-11(p<0.0001)$. Differences within CCI in patients lower than 75 years showed that the mean number of comorbidities was 5 (3-10), whereas in patients with age over 75 was 6 (4-11) (Fig. 1).

Arterial hypertension was frequently present and the majority of patients undergo combined therapies. Patients with dyslipidaemia receiving lipid lowering drugs were $6.5 \%$ in the first group and $11 \%$ in the second one, being statins and ezetimibe/omega- 3 the most administered drugs $(p<0.0001)$. Type 2 diabetes mellitus was treated in $19.5 \%$ in the first group and $22.6 \%$ in the second; in both groups, more than $50 \%$ of patients were treated with insulin, whereas metformin was the most commonly prescribed anti-diabetic drug. Osteoporosis therapy was administered in $6 \%$ within the first group and $14.6 \%$ within the second $(p<0.01)$. Therapies for gastrointestinal pathologies showed a high frequency in patients over 75 years $(p<0.0001)$, being protonpump inhibitors the mostly taken medications.

\section{Drug-drug interactions and de-prescribing}

As shown in Table 3, the number of medications taken by each patients before starting antiviral therapy was higher for those of age older than 75 years, and this difference was statistically significant $(p<0.0001)$.

After checking drug-drug interaction at Liverpool website for each patient, we start de-prescribing process. We found that drugs frequently suspended due to interaction with antivirals were within the second group ( $>75$ years) as compared with the first $(p<0.0001)$. One drug was suspended or replaced in $20.7 \%$ of patients ( $19.1 \%$ in the first group and $22.6 \%$ in the second group). A drug was suspended in $13 \%$ of patients in the first group and $15.6 \%$ in the second group. The most frequently suspended drugs due to 
Table 1 Baseline features of patients with HCV-related liver disease treated with DAA, stratified by age

\begin{tabular}{|c|c|c|c|}
\hline & $\begin{array}{l}65-74 \text { years } \\
n=215(52)\end{array}$ & $\begin{array}{l}\geq 75 \text { years } \\
n=199(48)\end{array}$ & $p<$ \\
\hline Male gender & $84(39)$ & $93(46.7)$ & ns \\
\hline $\mathrm{BMI}\left(\mathrm{Kg} / \mathrm{m}^{2}\right)$ & $26.8 \pm 3.8$ & $25.4 \pm 3.6$ & 0.0001 \\
\hline HCVRNA > 800.000 U/ml & $127(59.1 \%)$ & $121(60.8 \%)$ & ns \\
\hline \multicolumn{4}{|l|}{ Genotype } \\
\hline $1 b$ & 169 (78.6) & $167(84)$ & ns \\
\hline $1 \mathrm{a}$ & $7(3.2)$ & $2(1)$ & ns \\
\hline 2 & $27(12.6)$ & 27 (13.6) & ns \\
\hline 3 & $3(1.4)$ & 0 & ns \\
\hline 4 & $9(4.2)$ & $3(1.4)$ & ns \\
\hline ALT (IU/L) & $68.4(9-331)$ & $59.5(11-205)$ & ns \\
\hline $\mathrm{PTL} / \mathrm{mmc}$ & $169.705(320-414000)$ & $158.525(370-880000)$ & 0.05 \\
\hline Bilirubin (mg/dl) & $0.9 \pm 0.6$ & $0.8 \pm 0.5$ & ns \\
\hline Albumin (gr/dl) & $3.9 \pm 0.4$ & $3.8 \pm 0.4$ & ns \\
\hline INR & $1.07 \pm 0.24$ & $1.06 \pm 0.21$ & ns \\
\hline Fibroscan (KPa) & $11(2.9-70.6)$ & $11.9(3.2-74.6)$ & ns \\
\hline \multicolumn{4}{|l|}{ Stage of disease } \\
\hline Chronic hepatitis & $141(65.6)$ & $100(50.3)$ & 0.002 \\
\hline Cirrhosis & $74(34.4)$ & $89(49.7)$ & 0.05 \\
\hline $\mathrm{HCC}$ & $3(1.9)$ & $10(5)$ & ns \\
\hline Presence of varices & $34(45.9)$ & $49(55)$ & ns \\
\hline \multicolumn{4}{|l|}{ Child-pugh class } \\
\hline A & 70 (94.6) & $86(96.6)$ & ns \\
\hline B & $4(5.4)$ & $3(3.4)$ & ns \\
\hline \multicolumn{4}{|l|}{ Previous treatment: } \\
\hline Naive & $106(49.3)$ & $120(60.3)$ & ns \\
\hline Experienced & $109(51.7)$ & $79(39.7)$ & 0.03 \\
\hline \multicolumn{4}{|l|}{ Co-morbidities } \\
\hline Arterial hypertension & $147(68.4)$ & $152(76.4)$ & ns \\
\hline Cardiomyopathy & $8(3.7)$ & $11(5.5)$ & ns \\
\hline Diabetes mellitus & $42(19.5)$ & $45(22.6)$ & ns \\
\hline Dyslipidemia & $14(6.5)$ & $22(11)$ & 0.0001 \\
\hline Kidney disease & $7(3.3)$ & $12(5)$ & ns \\
\hline Prostatic hypertrophy & $18(8.4)$ & 27 (13.6) & ns \\
\hline Gastro-intestinal disease & $80(37.2)$ & $121(60.8)$ & 0.0001 \\
\hline Thyroid disease & $33(15.3)$ & $20(10)$ & ns \\
\hline Respiratory disease & $12(5.6)$ & $9(4.5)$ & ns \\
\hline Osteoporosis & $13(6)$ & $29(14.6)$ & 0.01 \\
\hline Depression & $22(10.2)$ & $8(4)$ & \\
\hline \multicolumn{4}{|c|}{ Charlson Comorbidities Index (score) } \\
\hline $3-5$ & $131(61)$ & $74(37)$ & 0.0001 \\
\hline $6-8$ & $82(38)$ & $105(53)$ & 0.005 \\
\hline $9-11$ & $2(1)$ & $20(10)$ & 0.0001 \\
\hline
\end{tabular}

interactions with antivirals were statins (21.4\% vs. $35.5 \%)$, proton pump inhibitors (21.4\% vs. $12.9 \%)$, bisphosphonates/ vitamin D (13\% vs. 15.6\%), and anti-hypertensive drugs (0 vs. $12.9 \%$ ). Anti-hypertensive drugs (57.2\% vs. $44.4 \%)$ followed by statins ( $21.4 \%$ vs. $22.2 \%$ ) in both groups were the most replaced with another medication of the same class
(6,5\% in the first group and $9 \%$ in the second) due to moderate or severe interaction with antiviral therapy, and thus, preventing the reliable occurrence of any adverse event leading to stopping antivirals (Table 4). Suspension and/or replacement of drugs have been closely carried-out through a close monitoring of the patients during the monthly visits. None 
Table 2 Comparison of Charlson Index in patients with HCV-related liver disease according to age groups

\begin{tabular}{llll}
\hline $\begin{array}{l}\text { Charlson Comor- } \\
\text { bidity Index }\end{array}$ & $\begin{array}{l}\text { 65-74 years } \\
n=215(52 \%)\end{array}$ & $\begin{array}{l}\geq 75 \text { years } \\
n=199(48 \%)\end{array}$ & $p<$ \\
\hline $\begin{array}{llll}\text { Score } \\
3\end{array}$ & $29(13.5 \%)$ & 0 & 0.0001 \\
4 & $72(33.5 \%)$ & $40(20.1 \%)$ & 0.003 \\
5 & $30(13.9 \%)$ & $34(17.1 \%)$ & $\mathrm{ns}$ \\
6 & $46(21.4 \%)$ & $51(25.6 \%)$ & $\mathrm{ns}$ \\
7 & $28(13.1 \%)$ & $38(19.2 \%)$ & $\mathrm{ns}$ \\
8 & $8(3.7 \%)$ & $16(8 \%)$ & $\mathrm{ns}$ \\
9 & 0 & $10(5 \%)$ & 0.001 \\
10 & $2(0.9 \%)$ & $8(4 \%)$ & 0.001 \\
11 & 0 & $2(1 \%)$ & $\mathrm{ns}$ \\
\hline
\end{tabular}

of the suspended or replaced drug have been re-entered within the medications taken at the end of antiviral therapy. Sometimes only dosage of anti-hypertensive drugs have been increased with the purpose of the reaching therapeutic range, when antiviral therapy have been completed.

\section{Discussion}

Availability of DAAs allowed elder people to access antiviral treatment safely, with response rates of more than $95 \%$, regardless of comorbidities. Thus, a careful assessment of the patient's geriatric status is mandatory before starting DAAs regimen.

In our study, we found that among 414 elder patients studied, percentage rates of women treated was higher than males, BMI was lower and cirrhosis was frequently reported in patients older than 75 years. CCI showed lower scores in the first group as compared with the second, in which scores were significantly higher $(p<0.0001)$. Arterial hypertension was the comorbidity most frequent, followed by type 2 diabetes, dyslipidemia and osteoporosis; classes of drugs most administered were statins, which were also the most frequently suspended, following by proton pump inhibitors, bisphosphonates/vitamin D; antihypertensive drugs were the most replaced medications.

Percentage of elderly patients with $\mathrm{HCV}$ infection treated was very low before the introduction of the DAAs [13] and this was mainly due to the high number of comorbidities, which constituted an absolute contraindication in the era of IFN/RBV treatment [10]. However, with the introduction of DAAs regimen, it was possible to increase the number of elder patients treated [24], as was shown in our cohort, as well.

As already noted, clinical features of our cohort regarding genotype and stage of liver disease confirm the epidemiological data of HCV infection in Italy [25, 26], thus patients started DAAs regimens according to AIFA criteria, in force at the time of prescription. In general, all treatment schedules were well tolerated; no patient died during antiviral therapy, nor in the following 6 months. Adverse events within the entire cohort were reported only in five cases, two
Fig. 1 Analysis of differences within $\mathrm{CCI}$ in patients younger and older than 75 years: mean number of comorbidities was 5 (3-10) in younger and $6(5-11)$ in older than 75

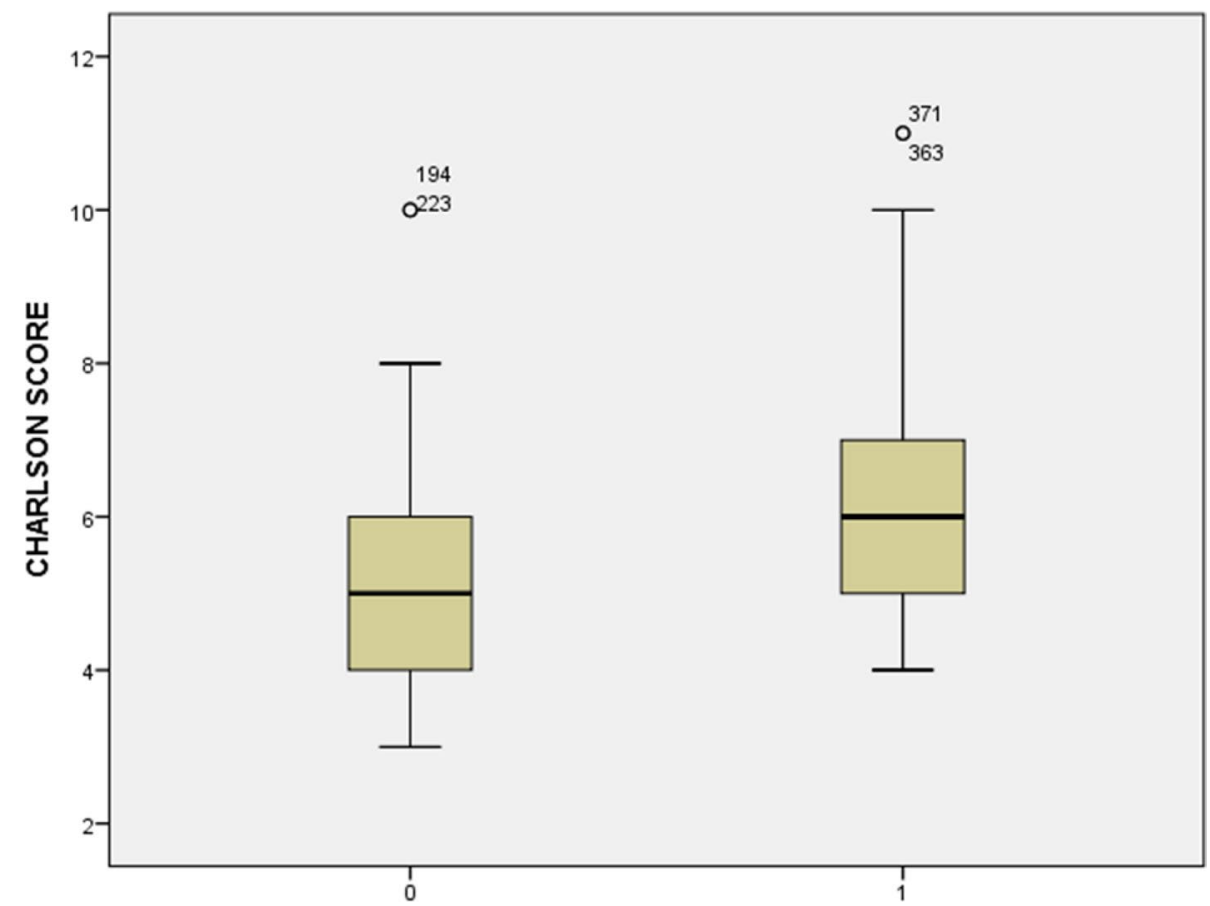


Table 3 Number of medications taken by each patients with chronic HCV-related liver disease stratified by age and de-prescribing after checking DDI interaction

\begin{tabular}{|c|c|c|c|}
\hline Medications & $\begin{array}{l}65-74 \text { years } \\
n=215(52 \%)\end{array}$ & $\begin{array}{l}\geq 75 \text { years } \\
n=199(48 \%)\end{array}$ & $p<$ \\
\hline $0-3$ & $137(63.7 \%)$ & $85(42.7 \%)$ & $0.0001 *$ \\
\hline $4-7$ & $68(31.6 \%)$ & $101(50.8 \%)$ & \\
\hline $8-11$ & $10(4.7 \%)$ & $13(6.5 \%)$ & \\
\hline De-prescribing & $\begin{array}{l}65-74 \\
n=215(52 \%)\end{array}$ & $\begin{array}{l}\geq 75 \\
n=199(48 \%)\end{array}$ & $p$ \\
\hline $0-3$ & $141(65.6)$ & $91(42.7 \%)$ & 0.0001 \\
\hline $4-7$ & $66(30.7 \%)$ & $99(50.8 \%)$ & \\
\hline $8-11$ & $8(3.7 \%)$ & $9(6.5 \%)$ & \\
\hline
\end{tabular}

${ }^{*} \rho=0.2$

Table 4 Analysis of drugs suspended or replaced for patients with HCV-related liver disease before starting DAAs, stratified by age

\begin{tabular}{llll}
\hline De-prescribing & $\begin{array}{l}65-74 \text { years } \\
n=215(52 \%)\end{array}$ & $\begin{array}{l}\geq 75 \text { years } \\
n=199(48 \%)\end{array}$ & $p<$ \\
\hline Total: 86(20.7\%) & $41(19.1 \%)$ & $45(22.6 \%)$ & $\mathrm{ns}$ \\
Suspension 1 drug & $28(13 \%)$ & $31(15.6 \%)$ & $\mathrm{ns}$ \\
Bisphosphonates/vitamin D & $11(39.3 \%)$ & $9(29 \%)$ & $\mathrm{ns}$ \\
Statins & $6(21.4 \%)$ & $11(35.5 \%)$ & $\mathrm{ns}$ \\
Anti-hypertensive & 0 & $4(12.9 \%)$ & 0.05 \\
PPI & $6(21.4 \%)$ & $4(12.9 \%)$ & $\mathrm{ns}$ \\
Other & $5(17.9 \%)$ & $3(9.7 \%)$ & $\mathrm{ns}$ \\
Substitution 1 drug & $14(6.5 \%)$ & $18(9 \%)$ & $\mathrm{ns}$ \\
Statins & $3(21.4 \%)$ & $6(33.3 \%)$ & $\mathrm{ns}$ \\
Anti-hypertensive & $8(57.2 \%)$ & $8(44.4 \%)$ & $\mathrm{ns}$ \\
Other & $3(21.4 \%)$ & $4(22.2 \%)$ & $\mathrm{ns}$ \\
\hline
\end{tabular}

in the first group and three in the second as described above; none of them was correlated to aging. There were no substantial differences in terms of SVR between the two groups, confirming results obtained from other cohorts $[13,14,24]$. In patients over 75 years, an increased number of medication intake and reduced glomerular filtrate (GFR) prevailed. In this population, elbasvir/grazoprevir, which is indicated for patients with reduced GFR, was the most prescribed DAAs as compared with patients younger (65-74 years). Moreover, among DAAs, it represents the medication with fewer drug interactions on Liverpool website and thus useful for older patients on poly-therapy.

Low BMI in these patients denotes that a mild sarcopenia, typical of the elderly cirrhotic patient, was frequent [27]. Mild sarcopenia is consistent with advanced age, cirrhosis and osteoporosis and accordingly these comorbidities were features typically of our cohort, in which patients older than 75 years had a BMI lower than those aged $64-75$ years.
In elderly patients, comorbidities are numerous, actively contribute to the progression of HCV-related disease and further decreases quality of life [2]. We calculated the Charlson Comorbidity Index [16], which predicts the 1-year mortality for a comorbid condition and how aggressively to treat it. More than half $(61 \%)$ of our patients in the group of 65-74 years had a CCI less than 5, whereas more than $50 \%$ of the patients aged more than 75 years had a score between 6 and 8 (Fig. 2). Thus, as it has showed by Ruzicka et al. [28], increasing age is associate with a major number of diseases.

The concept of comorbidity is usually associated with the poly-therapy, and elderly patients are currently being prescribed with a median of seven medications, which often causes more harm than benefit, and emphasizes the importance of "de-prescribing" [29]. This process consistent with tapering, stopping, discontinuing, or withdrawing drugs, with the goal of managing polypharmacy, improve the appropriateness of prescriptions and clinical outcomes. In our study, one drug was suspended or replaced in $20.7 \%$ of patients, stopped in about $15 \%$. The most frequently suspended and/or replaced drugs were: bisphosphonates/vitamin D, proton-pump inhibitors, statins and anti-hypertensive drugs. In particular, arterial hypertension was the most frequent comorbid condition in both groups, since it perfectly correlates with other published studies [30, 31]. The need of anti-hypertensive therapy, with one or more medication, in the elderly is rigorously associated to the risk of complications due to atherosclerosis and cardiac abnormalities, as increasing of left ventricular mass, which represent the major risk factor for transient ischemic attack and stroke $[32,33]$. Given such potential drug interactions with DAAs, needed medications to avoid above complications should be adequately replaced. Accordingly, the highest number of substituted drugs to avoid harmful events leading to stopping antivirals have been found in hypertensive patients, within the following category of drugs: calcium-channels blockers, 


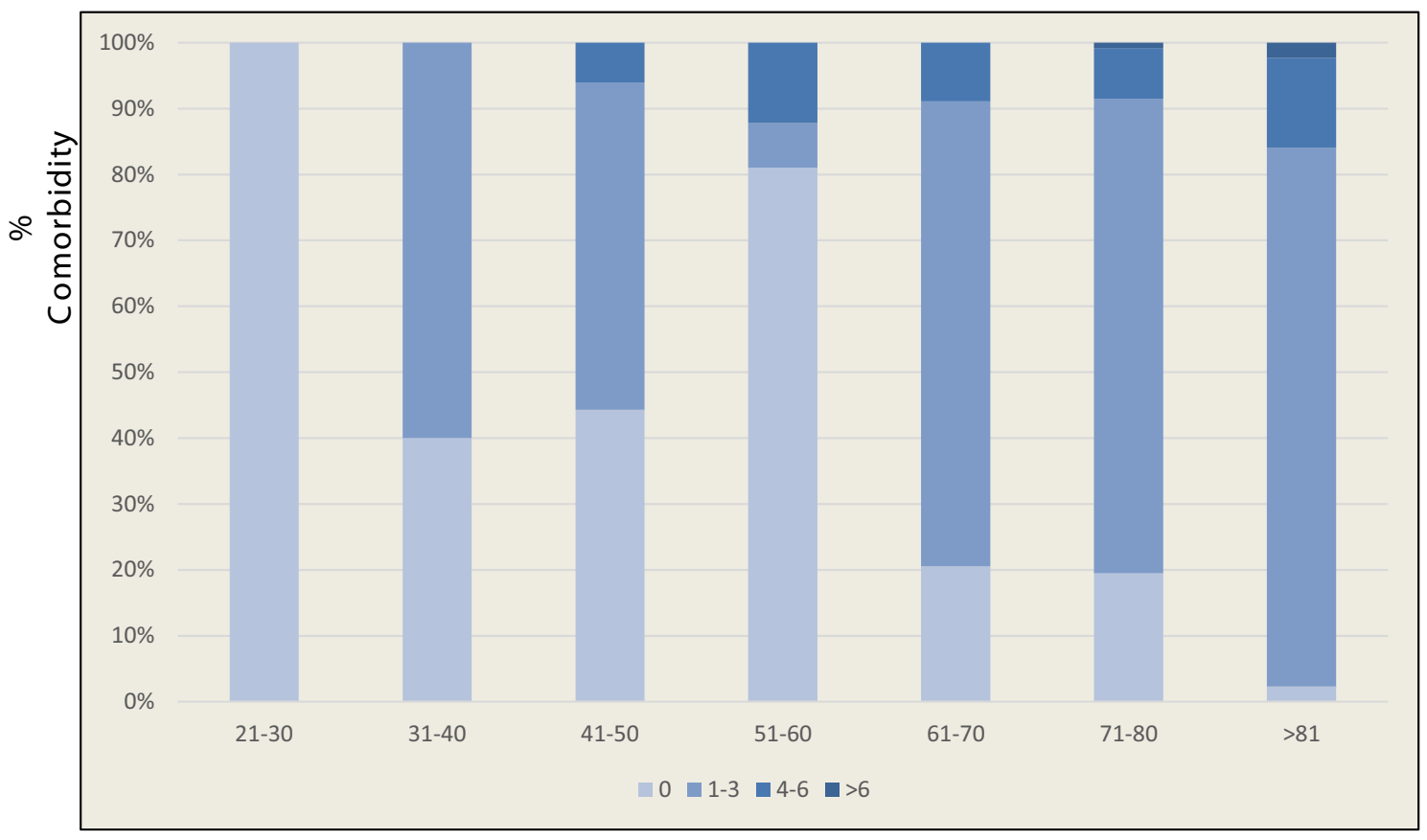

Age Classes

Fig. 2 Analysis of percentages of comorbidities 1-3, 4-6,>6, according different age classes (years)

heart failure agents and statins. As regards to osteoporosis, de-prescribing of vitamin D/bisphosphonate was frequently performed not because of drug interactions, but aiming to improve compliance to antiviral therapy in patients on polytherapy, sometimes following the Beers criteria, as well [34].

The new DAAs, although safe and effective, present an important number of drug interactions, which if not properly evaluated could compromise the outcome of the treatment and, therefore, the patient's health, as also underlined in the observational cohort of PITER study $[35,36]$. In our study, no significant adverse events caused by drug interactions have been detected. This was probably due to the careful assessment of drug-drug interactions before starting antiviral therapy, followed by the close clinical monitoring. Furthermore, following the end of antiviral treatment, patients usually continued to practice therapy as it has been prescribed, before starting DAAs, with an overall reduction in the number of drugs taken, in accordance with pharmaco-economics principles and decreasing health costs.

In conclusion, advanced age should not be considered a barrier to antiviral treatment, as the safety profile found was optimal as compared with the high number of comorbidities and concomitant medications. In our study, we have shown that DAAs determines a high rate of response in elderly population, regardless of disease severity and comorbidity. Overall, de-prescribing in these complex patients constitutes a step forward in the prevention of adverse events, representing a real improvement for the quality of life, as well.

Supplementary Information The online version contains supplementary material available at https://doi.org/10.1007/s11739-021-02741-9.

Author contributions AL, MGM, MS-concept and design of the study and helped draft the article; MGM, FAM, LM, CL and SAcollected data; MS — analysed data; LG, MGM, GM — contributed to study design. All authors approved the final version of the manuscript.

Funding Open access funding provided by Università degli Studi di Palermo within the CRUI-CARE Agreement. None to declare.

\section{Declarations}

Conflict of interest The authors declare they have no conflict of interest.

Statement of human and animal rights The study including human participants has been performed in accordance with the ethical standards of the Declaration of Helsinki and its later amendments.

Informed consent All patients provide written informed consent.

Open Access This article is licensed under a Creative Commons Attribution 4.0 International License, which permits use, sharing, adaptation, distribution and reproduction in any medium or format, as long as you give appropriate credit to the original author(s) and the source, provide a link to the Creative Commons licence, and indicate if changes were made. The images or other third party material in this article are included in the article's Creative Commons licence, unless indicated 
otherwise in a credit line to the material. If material is not included in the article's Creative Commons licence and your intended use is not permitted by statutory regulation or exceeds the permitted use, you will need to obtain permission directly from the copyright holder. To view a copy of this licence, visit http://creativecommons.org/licenses/by/4.0/.

\section{References}

1. EASL (2018) EASL recommendations on treatment of hepatitis C 2018. Clinical practice guidelines. J Hepatol 69:461-511

2. Vespasiani-Gentilucci U, Galati G, Gallo P, De Vincentis A, Riva E, Picardi A (2015) Hepatitis C treatment in the elderly new possibilities and controversies towards interferon-free regimens. WJG 21:7412-7426

3. Stroffolini T, Sagnelli E, Gaeta GB et al (2017) Characteristics of liver cirrhosis in Italy: evidence for a decreasing role of $\mathrm{HCV}$ aetiology. Eur J Intern Med 38:68-72. https://doi.org/10.1016/j. ejim.2016.10.012

4. Andriulli A, Stroffolini T, Mariano A et al (2018) Declining prevalence and increasing awareness of HCV infection in Italy: a population-based survey in five metropolitan areas. Eur J Intern Med 53:79-84. https://doi.org/10.1016/j.ejim.2018.02.015

5. Pawlotsky JM (2003) Hepatitis C virus genetic variability: pathogenic and clinical implications. Clin Liver Dis 7:45-66

6. Marcellin P, Asselah T, Boyer N (2002) Fibrosis and disease progression in hepatitis C. Hepatology 36:47-56

7. World Health Organization, Geneva (2017) Global Hepatitis Report 2017

8. Wang LS, D'Souza LS, Jacobson IM (2016) Hepatitis C-a clinical review. J Med Virol 88:1844-1855

9. EASL (2012) 2011 European Association of the study of the liver hepatitis C virus clinical practice guidelines. Liver Int 32(1):2-8

10. Cammà $\mathrm{C}$, Cabibbo $\mathrm{G}$, Bronte $\mathrm{F}$ et al (2009) Retreatment with pegylated interferon plus ribavirin of chronic hepatitis $\mathrm{C}$ nonresponders to interferon plus ribavirin: a meta-analysis. J Hepatol 51(4):675-681. https://doi.org/10.1016/j.jhep.2009.06.018

11. Geddawy A, Ibrahim YF, Elbahie NM, Ibrahim MA (2017) Direct acting anti-hepatitis $\mathrm{C}$ virus drugs: clinical pharmacology and future direction. J Transl Intern Med 5(1):8-17

12. Asselah T, Boyer N, Saadoun D, Martinot-Peignoux M, Marcellin P (2016) Direct-acting antivirals for the treatment of hepatitis C virus infection: optimizing current IFN-free treatment and future perspectives. Liver Int 36(Suppl 1):47-57

13. Gramenzi A, Conti $\mathrm{F}$, Cammà $\mathrm{C}$, Grieco $\mathrm{A}$, Picciotto $\mathrm{A}$, Furlan $C$ et al (2012) Hepatitis $C$ in the elderly: a multicentre crosssectional study by the Italian Association for the study of the liver. Dig Liver Dis 44:674-680

14. Conti F, Brillanti S, Buonfiglioli F, Vukotic R, Morelli MC et al (2017) Safety and efficacy of direct-acting antivirals for the treatment of chronic hepatitis $\mathrm{C}$ in a real-world population aged 65 years and older. J Viral Hepat. 24:454-463

15. Fillenbaum GG, Pieper CF, Cohen HJ, Cornoni-Huntley JC, Guralnik JM (2000) Comorbidity of five chronic health conditions in elderly community residents: determinants and impact on mortality. J Gerontol 55A(2):M84-M89

16. Charlson ME, Pompei P, Ales KL, MacKenzie CR (1987) A new method of classifying prognostic comorbidity in longitudinal studies: development and validation. J Chronic Dis 40(5):373-383

17. Keast SL, Holderread B, Cothran T, Skrepnek GH (2019) Hepatitis $\mathrm{C}$ direct-acting antiviral treatment selection, treatment failure, and use of drug-drug interactions in a state medicaid program. $\mathrm{J}$ Manag Care Spec Pharm 25(11):1261-1267
18. Pasina L, Brignolo Ottolini B, Cortesi L, Tettamanti M, Franchi C, Marengoni A et al (2019) Need for deprescribing in hospital elderly patients discharged with a limited life expectancy: the REPOSI Study. Med Princ Pract 28(6):501-508

19. Mannucci PM, Nobili A, Pasina L, REPOSI Collaborators (2018) Polypharmacy in older people: lessons from 10 years of experience with the REPOSI register. Intern Emerg Med 13(8):1191-1200

20. Calvaruso V, Cacciola I, Licata A et al (2019) Is transient elastography needed for noninvasive assessment of high-risk varices? The REAL experience. Am J Gastroenterol 114(8):1275-1282. https://doi.org/10.14309/ajg.0000000000000266

21. Zu Siederdissen CH, Maasoumy B, Marra F et al (2016) Drugdrug interactions with novel all oral interferon-free antiviral agents in a large real-world cohort. Clin Infect Dis 62:561-567

22. Vermehren J, Peiffer KH, Welsch C, Grammatikos G, Welker MW, Weiler $\mathrm{N}$ et al (2016) The efficacy and safety of direct acting antiviral treatment and clinical significance of drug-drug interactions in elderly patients with chronic hepatitis $\mathrm{C}$ virus infection. Aliment Pharmacol Ther 44(8):856-865

23. Scott IA, Hilmer SN, Reeve E et al (2015) Reducing inappropriate polypharmacy: the process of deprescribing. JAMA Intern Med 175(5):827-834. https://doi.org/10.1001/jamainternmed.2015. 0324

24. Su F, Beste LA, Green PK, Berry K, Ioannou GN (2017) Directacting antivirals are effective for chronic hepatitis $\mathrm{C}$ treatment in elderly patients: a real-world study of 17487 patients. Eur J Gastroenterol Hepatol 29(6):686-693

25. Messina JP, Humphreys I, Flaxman A, Brown A, Cooke GS, Pybus OG, Barnes E et al (2015) Global distribution and prevalence of hepatitis $C$ virus genotypes. Hepatology 61:77-87

26. Reid M, Price JC, Tien PC (2017) Hepatitis C virus infection in the older patient. Inf Dis Clin North Am 31:827-838

27. Ebadi M, Bhanji RA, Tandon P, Mazurak V, Baracos VE, Montano-Loza AJ (2020) Prognostic significance of body composition abnormalities in patients with cirrhosis. Aliment Pharmacol Ther 52:600-618. https://doi.org/10.1111/apt.15927

28. Ruzicka DJ, Tetsuka J, Fujimoto G, Kanto T (2018) Comorbidities and co-medications in populations with and without chronic hepatitis C virus infection in Japan between 2015-2016. BMC Infect Dis 18(1):237. https://doi.org/10.1186/s12879-018-3148-Z

29. Williams S, Miller G, Khoury R, Grossberg GT (2019) Rational deprescribing in the elderly. Ann Clin Psychiatry 31(2):144-152

30. Virdis A, Bruno RM, Neves MF, Bernini G, Taddei S, Ghiadoni L (2011) Hypertension in the elderly: an evidence-based review. Curr Pharm Des 17(28):3020-3031

31. Borghi C, Pavesi A (2013) Guidelines for hypertensive elderly. J Gerontol 61:161-166

32. Parrinello G, Colomba D, Bologna P, Licata A et al (2004) Early carotid atherosclerosis and cardiac diasolic abnormalities in hypertensive subjects. J Hum Hypertens 18:201-205

33. Licata G, Scaglione R, Corrao S et al (1995) Heredity and obesity associated hypertension: impact of hormonal characteristics and left ventricular mass. J Hypertens 13:611-618

34. American Geriatrics Society (2015) Beers criteria update expert panel. American Geriatrics Society 2015 updated beers criteria for potentially inappropriate medication use in older adults. J Am Geriatr Soc 63(11):2227-2246

35. Kondili LA, Gaeta GB, Ieluzzi D et al (2018) Real-life data on potential drug-drug interactions in patients with chronic hepatitis $C$ viral infection undergoing antiviral therapy with interferon-free DAAs in the PITER Cohort Study. PLoS ONE 13(1):e0190803. https://doi.org/10.1371/journal.pone.0190803

36. Quaranta MG, Rosato S, Ferrigno L et al (2020) Real-life use of elbasvir/grazoprevir in adults and elderly patients: a prospective 
evaluation of comedications used in the PITER cohort. Antivir Ther 25(2):73-81. https://doi.org/10.3851/IMP3350
Publisher's Note Springer Nature remains neutral with regard to jurisdictional claims in published maps and institutional affiliations. 